\title{
PROJECT MUSE
}

\section{The China Challenge}

Cao, Huhua, Poy, Vivienne

Published by University of Ottawa Press

Cao, Huhua and Vivienne Poy.

The China Challenge: Sino-Canadian Relations in the 21st Century.

University of Ottawa Press, 2011.

Project MUSE. doi:10.1353/book.2097.

$\Rightarrow$ For additional information about this book

https://muse.jhu.edu/book/2097 


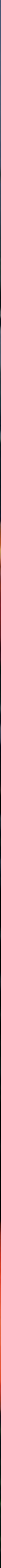

